\title{
Dysarthria and visual hallucinations due to flecainide toxicity
}

\author{
Essam Ramhamadany, Simon Mackenzie and David R. Ramsdale \\ Regional Cardiothoracic Unit, Broadgreen Hospital, Thomas Drive, Liverpool, L14 3LB, UK.
}

\begin{abstract}
Summary: A 65 year old man with recurrent ventricular tachyarrhythmias post myocardial infarction developed dysarthria and visual hallucinations due to flecainide toxicity. A readily available assay is required for estimating serum flecainide levels in patients with diminished renal or hepatic function or failed arrhythmia suppression.
\end{abstract}

\section{Introduction}

Flecainide acetate is a new Class $1 \mathrm{C}$ antiarrhythmic agent which stabilizes and slows conduction in atrial and ventricular myocardium, in conduction tissue and in accessory pathways. It has been shown to be effective against atrial, junctional and ventricular arrhythmias by increasing the QT interval and prolonging QRS duration. Serious central nervous system side effects are thought to be infrequent. We describe a case of failed arrhythmia suppression associated with dysarthria and visual hallucinations due to flecainide toxicity.

\section{Case report}

A 65 year old man with acute antero-lateral myocardial infarction developed ventricular fibrillation 10 days after admission. Post-cardioversion he was treated with intravenous lignocaine $(100 \mathrm{mg}$ bolus $+3.4 \mathrm{~g}$ in $36 \mathrm{~h}$ ). Recurrence of ventricular tachycardia necessitated adding intravenous $(300 \mathrm{mg}$ in $2 \mathrm{~h}+1.2 \mathrm{~g}$ in $24 \mathrm{~h}$ ) and oral amiodarone $300 \mathrm{mg}$ three times daily.

Recurrent ventricular fibrillation on the 14th day required cardioversion and further intravenous amiodarone. The following day ventricular fibrillation recurred, the serum amiodarone concentration was $1.9 \mathrm{mg} / 1$ (therapeutic range $0.15-4.5 \mathrm{mg} / \mathrm{l}$ ). Intravenous flecainide $(2 \mathrm{mg} / \mathrm{kg}$ bolus, $1.5 \mathrm{mg} / \mathrm{kg}$ in one hour then $0.25 \mathrm{mg} / \mathrm{kg} / \mathrm{h}$ for $15 \mathrm{~h}$ ) followed by oral flecainide $(200 \mathrm{mg}$ twice daily) were added to the treatment regimen with initial benefit. Sixty-five hours later, non-sustained ventricular tachycardia was followed by recurrent ventricular fibrillation. Intravenous flecainide $(2 \mathrm{mg} / \mathrm{kg}$ bolus then $0.25 \mathrm{mg} / \mathrm{kg} / \mathrm{h})$ was readministered with good initial effect. However,

Correspondence: D. Ramsdale, M.R.C.P., M.D.

Accepted: 10 September 1985 within 8 hours the patient developed dysarthria and visual hallucinations. The latter involved visions of family members and imagined objects held in his grasp. Persistence of these side effects and further episodes of ventricular tachycardia during intravenous flecainide therapy necessitated its replacement by intravenous and oral disopyramide with satisfactory results. Serum flecainide was found to be $2500 \mu \mathrm{g} / 1$ (therapeutic range $400-1000 \mu \mathrm{g} / \mathrm{l}$ ). Within 10 hours of withdrawing flecainide the dysarthria and the psychological disturbance subsided. Blood urea was $7.6 \mathrm{mmol} / \mathrm{l}$ on day 14 but at the time of toxicity was $19.2 \mathrm{mmol} / 1$. Plasma bilirubin rose from $22 \mathrm{mmol} / 1$ to $60 \mathrm{mmol} / \mathrm{l}$ on the day of toxicity and fell to $17 \mathrm{mmol} / \mathrm{l}$, 24 hours after stopping flecainide. Serum alkaline phosphatase similarly rose from $102 \mathrm{U} / 1$ to $260 \mathrm{U} / 1$ and fell to $186 \mathrm{U} / 1$.

\section{Discussion}

Flecainide is promptly and well absorbed after oral administration, metabolized by the liver and excreted in the urine. As much as $50 \%$ may be excreted by the kidney as unchanged drug and hence the long plasma half-life (12-27 hours) may be even more prolonged in patients with diminished renal function. This may explain the rapid development of toxicity in our patient.

Although adverse effects have been reported to occur in as many as $15-20 \%$ of patients (Cronheim, 1982) they are generally minor, involving blurred vision, tremor, dizziness, fatigue, nausea and constipation. Our experience suggests that significant amounts of drug may cross the blood-brain barrier when high levels are present in the blood and may be responsible for producing dysarthria and visual hallucinations. Similar effects have been reported with tocainide, (Currie \& Ramsdale, 1984) and lignocaine (Turner, 
1982) toxicity. Moreover the serial rise and fall in bilirubin during flecainide therapy might also suggest direct hepatotoxicity.

Finally, since serious, paradoxical proarrhythmic effects such as increased ventricular ectopic beats, conversion of non-sustained to sustained ventricular tachycardia, new ventricular tachyarrhythmias including ventricular fibrillation may also occur during treatment with flecainide and since atrioventricular block can be exacerbated (Bexton et al., 1984; Lui et al., 1982), we suggest that serum levels should be closely monitored and dosage appropriately modified especially in patients with diminished renal or hepatic

\section{References}

BEXTON, R.S., HELlESTRAND, K.J., NATHAN, A.W., BANIM, S.O. \& CAMM, A.J. (1984). The provocation of unwanted arrhythmias by flecainide acetate. European Heart Journal, 5 (Suppl. B), 114.

CRONHEIM, G.E. (1982). Side effects of flecainide - worldwide experience. Flecainide Symposium, Bender, F., Cronheim, G.E. (eds). p. 211. Gustav Fischer Verlag: Stuttgart. function and in those given intravenous flecainide⿳⺈冂: an adjunct to an apparently ineffective oral regimen. This of course will only be practically possible with development of a reliable assay technique which is widely and readily available.

This case has been reported to the manufacturerrs and to the Committee on Safety of Medicines.

\section{Acknowledgements}

We thank Dr E.J. Epstein ror permitting us to report 而is case, and Miss S. Kelly for typing the manuscript.

CURRIE, P. \& RAMSDALE, D.R. (1984). Paranoid psychळ్sis due to tocainide toxicity. British Medical Journal, 288, 906 . (1982). Flecainide induced QT prolongation and ventricular tachycardia. American Heart Journal, 103, 56 9

TURNER, W.M. (1982). Lidocaine and psychotic reactions. Annals of Internal Medicine, 97, 149. 